\title{
Effect of Inter-pupillary Distance on Stereo-acuity
}

\author{
Fatima Iqbal, Komal Atta, Hashim Ali Khan, Amna Iqbal
}

\begin{abstract}
Objective: To determine the effect of interpupillary distance (IPD) on stereopsis and to compare this affect in male and female population.

Methodology:Descriptive cross-sectional study was conducted on 30 individuals of either gender with age ranging from 15 to 30 years. Sample was recruited by non-probability convenient sampling technique at Ophthalmology department of Madina Teaching Hospital, Faisalabad from August 2018 to December 2018. Individuals with any ocular pathology, un-corrected refractive error or drug users were excluded. Near IPD was measured using millimeter scale and stereopsis was evaluated using titmus fly test. Data was analyzed by SPSS 21 . P value $\leq 0.05$ was considered significant.

Results:Our study comprised of 30 subjects of aged range 15-30 years. 15 participants were male and 15 were females. IPD values for both genders were ranged between $62-66 \mathrm{~mm}$. mean IPD was $65 \pm 1.01 \mathrm{~mm}$ for male and $64.8 \pm 1.14 \mathrm{~mm}$ for female, no significant difference was observed in mean IPD among gender $(\mathrm{P}$ value $=0.41)$ by $\mathrm{t}$ test. Both male and females have high IPD and low depth of perception $(<40 \mathrm{sec}$ of arc $)$, no significant difference in levels of Stereopsis was noted among gender $(\mathrm{P}$ value $=0.36)$. Pearson's correlation showed significant relation between IPD and stereopsis. (Pvalue $\left.=0000^{*}\right)$.
\end{abstract}

Conclusion:We found higher IPD and low depth of perception among both genders.

Key Words: Depth perception, Inter-pupillary distance, Stereopsis.

\section{Introduction}

Stereopsis is believed to be the only powerful cue to depth perception. Horizontal retinal image disparity between the two points of the retina or extra-foveal points fuse to give a three dimensional image. ${ }^{1,2}$ Best single stereoscopic vision with depth perception are due to the fusion of disparate images. ${ }^{3}$ Stereo-acuity is best obtained when image is formed on noncorresponding points. ${ }^{4}$ Stereoacuity is a measure of the binocular visual function and it helps to judge the relative distances between the objects. Distance can affect stereopsis when visual system is incorporated with accommodation, convergence and cognitive factors. ${ }^{4}$ In stereopsis different image sizes or disparities are used by the optical system to obtain depth perception. ${ }^{4}$ These differences become larger as when viewing a particular object at the earliest distance. Each human eye has a certain threshold for

Fatima Iqbal

Lecturer

School of Optometry, The University of Faisalabad

.Dr. Komal Atta

Assistant Professor

The University of Faisalabad

Hashim Ali Khan

Consultant Optometrist

SEHHAT Foundation Hospital, Gilgit

Dr.Amna Iqbal,

Research Internee,

University of virginia USA

Corresponding Author:

Fatima Iqbal:

Email: Fatima.iqbal@uf.edu.pk depth perception. There are different factors contributing to the threshold of three-dimensional vision. There are many factors that affect the stereoacuity. These factors are age, gender, vergence movements and displaying distance from the target. ${ }^{2,3}$ Inter pupillary distances (IPD) is the distance between the centers of the two pupils. ${ }^{5}$ It determines the stereo separation of the two images which are combined in the brain to produce stereo visualization. IPD is affected by gender, race and age. ${ }^{5}$ Normative mean values for IPD reported by the recent past Pakistani studies are 60 to $63 \mathrm{~mm}$ for adults age ranged between 15 30 years. ${ }^{5,6}$ IPD values higher in males as compared to females. ${ }^{6}$ Similar values are also documented by Iranian study. ${ }^{7}$ Closer to these values Turkish study reported, 59 to $61 \mathrm{~mm}$ IPD values in Turkish population with approx. $2 \mathrm{~mm}$ higher in males as compared to females. ${ }^{8}$ Recent past study conducted in Karachi comparing the IPD among the various ethnicities of Pakistan reported longer IPD in Punjabi and Balochi ethnicities than Sindhi community, most probably due to broader skeletal frame of formers. ${ }^{5}$ Shafiee D and his colleagues reported that males have approx. $2 \mathrm{~mm}$ wider IPD than females and females have higher depth of perception. ${ }^{4}$ These results showed inverse relation between IPD and stereopsis. Osunwoke EA, study was also documented lower interpupillary distance with high stereopsis scores in women than in men. ${ }^{9}$ On contrary to above studies, Eom Y and his co- authors reported improvement in stereoacuity with increase in IPD. ${ }^{10}$ IPD 
plays a key role in the optical industry for properly dispensing glasses as it determines the depth perception by stereoscopically separating the two points perceived by the brain to produce the three-dimensional vision. ${ }^{1}$ In ideal spectacles, center of the ophthalmic lenses should coincide with the visual axis that passes from the center of pupils or equivalent to the IPD of a person for obtaining better stereoacuity.' Spectacle non-tolerance and prismatic effect is induced due to the decentration of the ophthalmic lenses and causes the distortion of stereopsis. ${ }^{1}$ Exact relationship between the IPD and stereopsis is required to be elucidated to aware the opticians about the prismatic effect over stereopsis and consider IPD while dispensing glasses for quality vision.

Materials and Methods

Descriptive cross-sectional study was conducted at Ophthalmology Department of Madina Teaching Hospital and The University of Faisalabad from August 2018 to December 2018. 30 healthy individuals of either gender of 15 to 30 years were recruited through nonrandomized convenient sampling technique. Individuals with un-corrected refractive errors, any past ocular and surgical history, strabismus, anisometropia, amblyopia, tropias, phorias and any systemic diseases affecting the vision were excluded. Ethical approval from institute and consent was taken from each subject according to Declaration of Helsinki. Visual acuity was tested from LCD Snellen's at 6 meter distance. Anterior and posterior segment of eye was also evaluated. Distance between two pupils was measured using a millimeter rule. We set a normal range of near IPD from 62 to 63 millimeters (normal range of IPD was taken from previous Pakistani studies). Individuals were asked to grab the ruler and to ensure a proper measurement, holding the ruler right above their eyes. Examiner sited at a distance of 20 centimeter from the subjects, they were asked to close their right eye while looking to examiner's nose with opened eye and holding the zero mark of millimeter ruler right above the exact center of persons left pupil. Then measure the distance of right pupil by opening the right eye and found the exact millimeter mark that fell on subject's right pupil. The numbers in millimeters that lines up with the center of subjects' pupil were noted. To measure stereopsis titmus fly test was used. Each subject was asked to wear the 3-D polaroid glasses and to look at a vectogragh that consisted of two plates in the form of booklet and appreciate the 3-D figure at a distance of 40 centimeters. The amount of disparity in images was measured in sec of arc and it was varied as 400-100 sec of arc and $800-40 \mathrm{sec}$ of arc within the test target.

\section{Statistical analysis}

Data analysis was done using SPSS 21. Quantitative variables like age and IPD values are presented as means and compare by t- test. Categorical variables like and gender is presented as frequency and compare by chi square test. Pearson correlation was used to assess the relation between IPD and stereopsis. $\mathrm{P}$ value $\leq 0.05$ was considered significant.

Results

Study comprised of 30 subjects of aged range 15-30 years. 15 participants were male and 15 were females. IPD values for both genders were ranged between $62-66$ $\mathrm{mm}$. mean IPD was $65 \pm 1.01 \mathrm{~mm}$ for male and $64.8 \pm$ $1.14 \mathrm{~mm}$ for female, no significant difference was observed in mean IPD among gender( 0.41 ) by t test. On analyzing the frequency of subjects with increase and normal IPD values we found that off 15 males, 14 had longer IPD ranging from $64 \mathrm{~mm}$ to $66 \mathrm{~mm}$ and only 1 had normal IPD ranging from $62 \mathrm{~mm}$ to $63 \mathrm{~mm}$. off total females 11 had increased IPD ranging from $64 \mathrm{~mm}$ to $66 \mathrm{~mm}$ and only 4 had normal IPD ranging from $62 \mathrm{~mm}$ to $64 \mathrm{~mm}$. Both genders have similar frequencies of longer IPD no significant difference was found in this respect $(\mathrm{P}$ value 0.142 ) (Table 1). Interestingly, we found low depth of perception in both genders. 13 males had less depth $(<40 \mathrm{sec}$ of arc) whereas 2 had more depth with $(>800$ sec of arc). 11 females had less depth $(<40 \mathrm{sec}$ of arc $)$ whereas 4 had more depth with ( $>800 \mathrm{sec}$ of arc) no significant difference in levels of Stereopsis was noted among gender (P value 0.36) (Table 2). Our results show that the majority of the study population of both genders has longer IPD with low depth of perception. Figure 1 is showing that the both genders have low levels of Stereopsis. Figure 2 is indicating that the subjects with higher IPD have low depth of perception and worsen sterioacuity. Pearson correlation shows significant inverse relation between the stereopsis and IPD (P values $0.000 *)$.

Table 1: Interpupillary distance (IPD) among gender $(\mathrm{N}=30)$

\begin{tabular}{|c|c|c|c|}
\hline \multirow{2}{*}{$\begin{array}{c}\text { Gender } \\
(\mathrm{N}=30)\end{array}$} & \multicolumn{2}{|c|}{ Interpupillary distance (IPD) } & \multirow{3}{*}{ Total (30) } \\
\cline { 2 - 3 } & $\begin{array}{c}\text { Normal IPD } \\
(62 \mathrm{~mm} \text { to 64mm) }\end{array}$ & $\begin{array}{c}\text { Increase IPD } \\
(66 \mathrm{~mm} \text { to } 67 \mathrm{~mm})\end{array}$ & \\
\cline { 2 - 3 } & Frequency $(\mathrm{n})$ & Frequency (n) & 15 \\
\hline Male (15) & 1 & 14 & 15 \\
\hline Female (15) & 4 & 11 & \\
\hline P value & \multicolumn{2}{|c|}{0.142} & \\
\hline
\end{tabular}

Comparison by $\mathrm{X}^{2}$ test, Statistically significant value at $\mathrm{P} \leq 0.05$ 
Figure 1: Graphical representation between gender and stereopsis

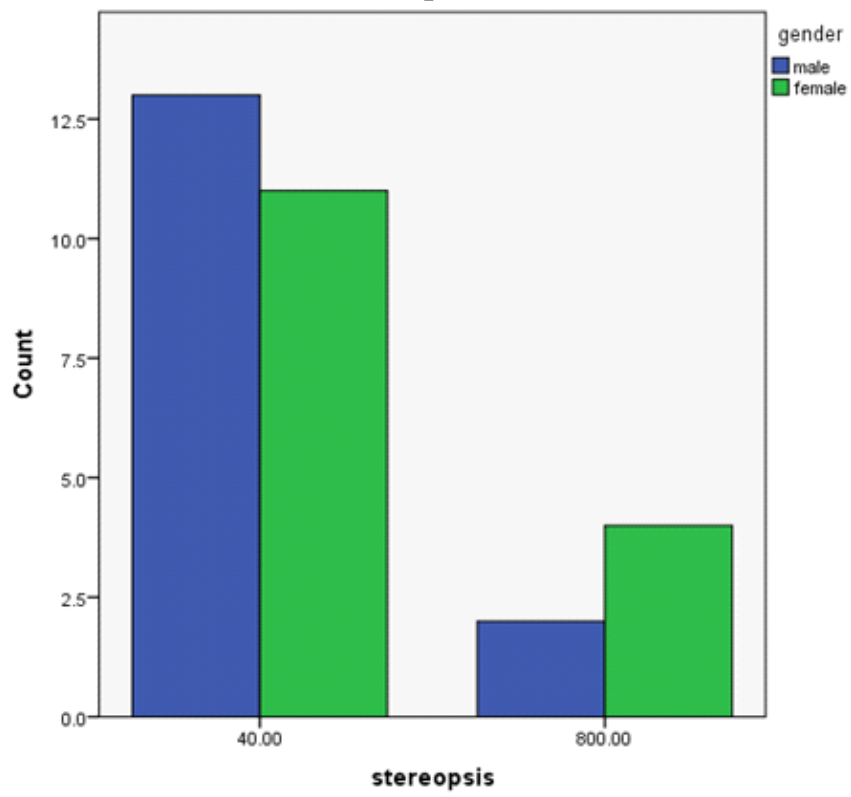

Table 2: Stereopsis among the Gender $(\mathbf{N}=\mathbf{3 0})$

\begin{tabular}{|c|c|c|c|}
\hline \multirow{2}{*}{$\begin{array}{c}\text { Gender } \\
(\mathrm{N}=30)\end{array}$} & $\begin{array}{c}\text { less depth } \\
(<40 \mathrm{sec})\end{array}$ & $\begin{array}{c}\text { More depth } \\
(>800 \mathrm{sec} \text { of arc })\end{array}$ & Total (30) \\
\cline { 2 - 4 } & Frequency (N) & Frequency( N) & \\
\hline Male (15) & 13 & 2 & 15 \\
\hline Female (15) & 11 & 4 & 15 \\
\hline P value & \multicolumn{3}{|c|}{0.361} \\
\hline
\end{tabular}

Comparison by $\mathrm{X}^{2}$ test, statistically significant value at $\mathrm{P} \leq 0.05$

Figure 2: Graphical relationship between IPD and stereopsis.

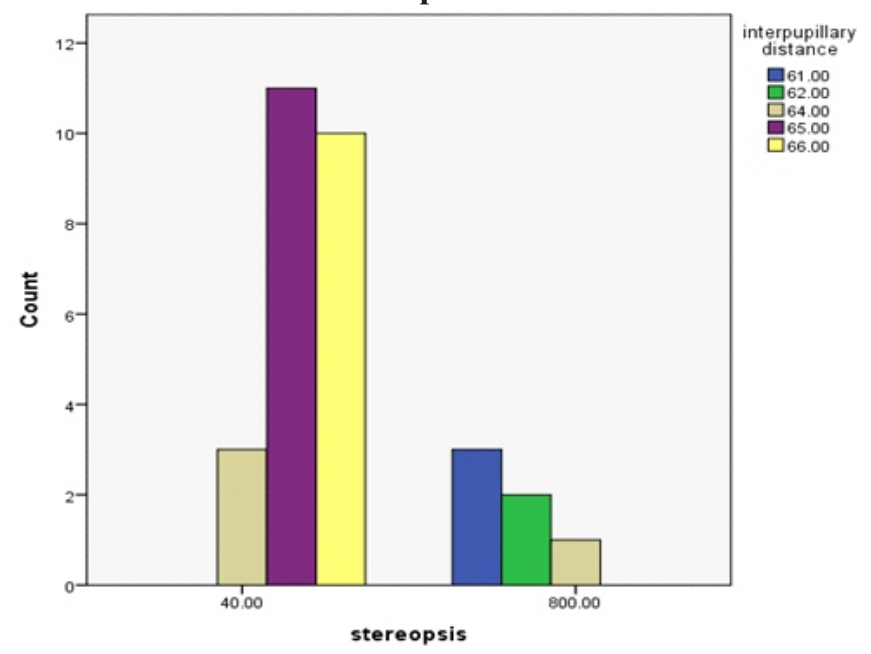

Discussion

This study was conducted to highlight the importance of interpupillary distance (IPD) and to explore its relation with stereopsis. IPD is the component of stereopsis which can influence stereoacuity. Evidences are available showing that people with smaller IPD can perceive depth in longer distance in contrast the individuals with larger IPD. It was also supported by few researches that females have smaller IPD and better stereoacuity than males. ${ }^{4,11}$
Conflicting to this Eom Y,et al documented the high depth of perception and improvement in stereoacuity with increase in IPD. ${ }^{10}$ However this link is yet to be clearly elucidated. The purpose of this study is to explore the relationship between stereopsis and IPD and to compare this among the gender. We tried to prove that size of the IPD has a significant effect on stereopsis. We achieved this by using range 40-800 seconds of arc of titmus fly test. Concerning the difference among the gender with respect to IPD $(\mathrm{P}=0.142)$ and stereopsis $(\mathrm{P}=0.361)$ nonsignificant difference was observed, but interestingly we found higher IPD and low depth of perception among both gender. IPD measurements of the majority of current study population were ranged between $64 \mathrm{~mm}$ to $66 \mathrm{~mm}$ among both genders, which are approx. $2 \pm 1 \mathrm{~mm}$, higher than other Pakistani, Iranian and Turkish studies. ${ }^{5,7,8,11}$ Pakistani study by Hayat $\mathrm{N}$ etal and Alkhairy S etal reported mean IPD of ranged 60 to $62 \mathrm{~mm}$, with higher values in males as compared to females. ${ }^{5,6}$ Hayat $\mathrm{N}$ also reported the higher IPD values in Punjabi population than Sindhi community, this is in agreement of our findings as we found higher IPD in our population than studies conducted in Karachi Sindh. ${ }^{5}$ Iranian study also reported the mean IPD of 61 to $63 \mathrm{~mm}$ in Iranian population. ${ }^{7}$ Our results proved that there is significant relationship between IPD and stereopsis $\left(\mathrm{P}=0.000^{*}\right)$. We found that with increase in IPD, depth of perception decreases resulting in poor sterioacuity. Our results are supported by Shafiee D etal who also reported the significant association between IPD and stereopsis. Shafiee D etal found that the subjects with high IPD have low depth of perception and worsening in sterioacuity. ${ }^{4}$ On contrary to our results, the same author documented the significant difference in IPD and stereopsis among the gender and found smaller IPD and high depth of perception among the females as compared to males. Another study conducted in Turkey also reported mean IPD values among males were $2 \mathrm{~mm} \pm 1.58 \mathrm{~mm}$ higher than that in females. $^{8}$ IPD measurements have significant role in optical industry. Ignorance of IPD during the dispensing of eyeglasses results in the poor image quality caused by marginal astigmatism, spherical aberration and chromatic aberration. Stereopsis is very important for accommodation while performing near tasks, Convergence and near focusing become harder because of the increased IPD. Opticians should be aware about the induced prismatic effect over stereopsis and consider IPD while dispensing glasses. We recommend that eye professionals must evaluate this factor while prescribing glasses and performing stereoacuity tests for improving the quality of vision. 


\section{Conclusion}

We found higher IPD and low depth of perception among both genders. A broader scale researches are required to establish the exact relationship between IPD and Stereopsis.

\section{Limitation}

Smaller sample size is the limitation of the study. Similar studies on larger scales should be conducted to evaluate the association between IPD and stereopsis.

Conflict of Interest:There is no conflict between authors and financial disclosures.

Funding Source: None

\section{References}

1.Arshad A, Choudhry AA, Hussain SJ, Latif I, Kalasra A.Effect of Spectacle Centration on Stereoacuity. Journal of Rawalpindi Medical College (JRMC); 2017; 21(2): 117-121.

2.Aslankurt M, Aslan L, Aksoy A, et al. Laterality does not affect the depth perception, but interpupillary distance. Journal of Ophthalmology.2013; 48(1):1-5. Kim.

3.SH, Suh YW, Yun C, Yoo E J, Yeom JH, Cho YA. Influence of stereopsis and abnormal binocular vision on ocular and systemic discomfort while watching 3D television Eye(Lond). 2013; 27(11): 1243-1248.

4. Shafiee D, Jafari AR, Shafiee AA. Correlation between Interpupillary Distance and stereo acuity. Bull. Env. Pharmacol. Life Sci. 2014; 13 (12): 26-33.
5.Hayat N, Alkhairy S, Cheema A, Ehsan M, Khan MA Normal interpupillary, inner canthal distance and outer canthal distance in a normal population of Pakistan.

Pak J Med Sci.2019;35(1):50-54.

6.Alkhairy S, Siddiquie F, Hassan M. Orbitofacial Anthroprometry in a Pakistani population. Pak J Ophthlmol. 2016;32(1):41-47.

7.Fesharaki H, Rezaei L, Farrahi F, Banihashem T, Jahanbakhshi A. Normal interpupillary distance values in an Iranian population. J Ophthalmic Vis Res. 2012; 7: $231-4$.

8.Yildirim Y, Ibrahim Sahbaz ,Kar T. Evaluation of interpupillary distance in the Turkish population. Clinical Ophthalmology .2015;9:1413-16.

9.Osunwoke EA, Didia BC, Olotu EJ, Yerikema AH. A Study on the Normal Values of Inner Canthal, Outer Canthal, Interpupillary Distance and Head Circumference of 3-21 Years Ijaws. Am. J. Sci. Ind. Res., 2012,3(6): 441-445.

10.Eom Y, Song JS, Ahn SE, Kang SY, Suh YW, Oh J, Kim SH, Kim HM Effects of interpupillary distance on stereoacuity: the Frisby Davis distance stereotest versus a 3-dimensional distance stereotest.Jpn J Ophthalmol. 2013;57(5):486-92.

11.Usman YM, Shugaba AL. The Interpupillary Distance and The Inner and Outer Canthal Distances. E3 J Sci Res. 2015;3(1):001-003. https://pdfs.semanticscholar.org/a1d1/29b0947f7c514d 648f2cea15be514ded62f7.pd.

\section{Author`s Contribution}

Fatima Iqbal: Study design, data collection, manuscript, writing, revise and approved the manuscript.

Dr. Komal Atta: Study design, data collection, result interpretation, write up of manuscript, editing and formulation of tables, revise and approve the manuscript.

Hashim Ali Khan: Study design, supervise throughout the research, manuscript writing, revise all the contents and approve the manuscript.

Dr. Amna Iqbal: Study design, data analysis, and interpretation of results, editing and formatting the manuscript. Reviewed and approved the manuscript. 